\title{
As Fases do Estudo Sobre Regulação da ECONOMIa Na SENSIBILIDADE JURIDICA BRASILEIRA
}

José Vicente Santos de Mendonça*

1 Introdução: propósito e roteiro do artigo. 2 Características do debate sobre direito regulatório no Brasil: sincrético, desigual e voltado ao Estado. 3 Antigamente: a pré-história do direito regulatório brasileiro. 4 Ontem: a etapa conceitual-constitucional. 5 Hoje: a etapa eficacial. 6 Encerramento: duas propostas para o novo vintênio do direito regulatório brasileiro. Referências.

\section{RESUMO}

Num primeiro momento, o texto identifica três características do debate jurídico sobre a regulação da economia no Brasil: ele é sincrético, desigual, e voltado ao Estado. Após, o artigo se dedica às fases do debate sobre regulação na sensibilidade jurídica brasileira. De uma pré-história da regulação, em que o assunto era apresentado de modo indistinto ao Direito Constitucional e ao Direito Administrativo, passou-se, em meados dos anos noventa, à etapa conceitual-constitucional, centrada na identificação constitucional das potestades regulatórias. Hoje, vive-se etapa eficacial, em que a ênfase recai no debate a respeito de sua qualidade. $\mathrm{O}$ artigo se encerra sugerindo duas linhas de ação para tornar nosso debate sobre regulação econômica mais original, mas sem perder a diversidade de abordagens que lhe é característica.

Palavras-chave: Direito Administrativo. Direito Econômico. Direito Regulatório. Regulação. Agências reguladoras.

\section{INTRODUÇÃO: PROPÓSITO E ROTEIRO DO ARTIGO}

Este é um artigo sobre a doutrina; é um meta-artigo. Seu propósito é o de narrar, a um público não inteiramente familiarizado com o tema, as etapas do debate jurídico sobre regulação da economia no Brasil. ${ }^{1}$

Um texto assim construído leva, de imediato, a dois tipos de preocupações: a primeira é com a fidedignidade da descrição; a segunda é o risco de se estar adotando uma espécie de teleologia doutrinária, em que fases "menos evoluídas" seriam superadas por fases "mais evoluídas".

* Doutor e mestre em Direito Público pela UERJ. LLM pela Universidade Harvard. Professor adjunto de Direito Administrativo da Universidade do Estado do Rio de Janeiro. Professor do programa de pós-graduação em Direito da Universidade Veiga de Almeida. Contato: jose.vicente@terra.com.br. 
Pois bem: a melhor forma de vencer um medo é assumindo-o. Este artigo, então, de fato, irá estereotipar posições. Provavelmente nenhum autor, mesmo que caracteristicamente pertencente a um estilo, irá subscrever todas as posições assumidas como típicas de sua fase. ${ }^{2}$ Mas o estereótipo é estratégia metodológica, que permite ressaltar aspectos que visões mais nuançadas esconderiam. ${ }^{3}$

O risco da vindicação de uma teologia doutrinária é mais problemático. E ele surge desde o título: ao se falar em etapas ou fases, pode-se ler, pelas entrelinhas, uma narrativa heróica, em que se reconstruísse o passado à luz de certo presente. Assim, tal como cogita Benjamin, a história, e aqui a história das doutrinas jurídicas, seria o cortejo triunfal dos vencedores. ${ }^{4}$ Não é este, contudo, o caso. Estilos são, apenas, formas de se entender e de se fazer algo. ${ }^{5}$ Etapas ou fases devem ser entendidas, neste texto, como momentos de prevalência de estilos, e não como degraus ordenados. Aliás, estilos não são melhores ou piores em relação aos outros; há, decerto, estilos mais e menos complexos, mas, se se trata de julgá-los, o máximo que se pode dizer é que são mais ou menos adaptados ao meio que os circunda.

Em termos estruturais, o texto procede da seguinte forma. O item 2 identifica três características do debate jurídico sobre regulação da economia no Brasil. Algumas delas são, antes, aspectos da própria doutrina jurídica brasileira. O debate brasileiro sobre regulação da economia seria metodologicamente sincrético; seria, ainda, desigual em interesses, premissas e qualidade; e seu foco primordial seria no Estado, e não na sociedade. É antes debate sobre regulação pública da economia do que sobre regulação da economia tout court.

Logo após, o item 3 identifica os primeiros momentos da análise jurídica brasileira sobre a regulação da economia. Neste momento inaugural, o Direito Regulatório possuía particularidade: era um direito que não era. Era Direito Constitucional ou Direito Administrativo. Não era Direito Regulatório.

A partir de certo momento no início dos anos noventa, o Direito Regulatório brasileiro descobriu-se a si mesmo - o marco foi a criação da primeira agência reguladora federal, a ANEEL, em 1996 -, e, com a volúpia dos jovens, começou a se perguntar quem era e qual o seu lugar no mundo. Eis a fase conceitual-constitucional, à qual é dedicado o item 4.

Hoje, já - parcialmente - resolvidos alguns desses dilemas, vive-se a etapa eficacial, em que as discussões estão centradas na qualidade da regulação da economia. É o tema do item 5.

O item 6, encerramento do trabalho, volta-se aos dilemas do presente. Nele, são destacadas possíveis ações a serem empreendidas, de modo a tornar o debate jurídico brasileiro sobre regulação na economia mais próprio e mais próximo, ainda que preservando a qualidade que há em sua diversidade. 


\section{CARACTERÍSTICAS DO DEBATE SOBRE DIREITO REGULATÓRIO NO BRASIL: SINCRÉTICO, DESIGUAL E VOLTADO AO ESTADO}

O debate sobre o Direito Regulatório, no Brasil, é caracteristicamente (i) sincrético, (ii) desigual, e (iii) voltado ao Estado. Explica-se.

Ele é (i) sincrético, seja em métodos, seja em referências teóricas. Virgílio Afonso da Silva identificou a característica do sincretismo metodológico a partir da doutrina brasileira voltada à interpretação da Constituição. ${ }^{6}$ Nossa doutrina da interpretação constitucional fala ora em ponderação de princípios, ora em interpretação constitucional estruturante, sem se importar, ou talvez conhecer, que, na origem teórica alemã, os conceitos são mutuamente excludentes.

Embora discordando, em parte, do tom crítico do artigo de Virgílio Afonso da Silva - pode-se ser sincrético não por desconhecimento, mas por opção; e tal opção pode se revelar adequada ao contexto de reflexão e aplicação do Direito no Brasil ${ }^{7}$-, é possível estender sua análise ao campo do Direito da Regulação.

De fato: no Brasil, também o debate jurídico sobre regulação da economia é metodologicamente sincrético. Não há adoção majoritária de um método cognitivo ou operacional. ${ }^{8}$ Há, no entanto, proximidade cada vez maior em relação à academia e à prática norte-americana, sem que isso implique colonização plena, vez que o referencial europeu, que está no DNA de nosso Direito Administrativo, ainda é muito presente. Isso não é, em si, nem ruim, nem bom: é o que somos.

Por exemplo: trecho da obra de Carlos Ragazzo, sobre revisão judicial de marcos regulatórios ${ }^{9}$, discute aspectos de microeconomia com base em referências norte-americanas, e, na conclusão, busca associá-los à forma leve de "princípio da proporcionalidade", lugar argumentativo próximo da práxis europeia. ${ }^{10} \mathrm{Tal}$ percurso dificilmente seria percorrido por autor americano ${ }^{11}$.

Observe-se, no entanto, que é discutível se tal sincretismo é característica do Direito Regulatório brasileiro, ou se, antes disso, está associado, como um todo, ao Direito Regulatório europeu continental contemporâneo. ${ }^{12}$ Vê-se, por exemplo, que obras francesas recentes também se aproximam de formas americanas. ${ }^{13}$

Talvez seja mais realista afirmar que, tal como ocorre na Europa, o debate brasileiro a respeito da regulação econômica vem se aproximando dos Estados Unidos. E, como nosso debate jurídico sobre Direito Público sempre foi, para o bem e para o mal, sincrético, em nosso país tal hibridismo de referências e de métodos encontra solo fértil.

Somos sincréticos, ainda, de um segundo modo: na busca por harmonizar teorias. Aqui, Posner e Dworkin podem aparecer, na mesma página, defendendo a mesma posição. Somos o país dos acordos teóricos incompletos. ${ }^{14} \mathrm{O}$ estereótipo de apresentação de uma determinada categoria conceitual é o seguinte: narra-se o que seria o extremo A; o que seria o extremo B; e se afirma, como posição ideal, um tertius, a qual corresponderia a uma posição intermediária, mista, híbrida, ou moderada. 
Pode-se ler tal prática sob duas óticas: ou a da superficialidade - o autor ignora que as posições são inconciliáveis - ou a do otimismo - talvez as diferenças não sejam tão graves. Do sincretismo decorre uma crença na plasticidade quintessencial das teorias jurídicas, e daí, no hibridismo radical.

Outro aspecto do debate sobre o Direito Regulatório brasileiro: além de sincrético - ao misturar, conciliatoriamente, autores e métodos - ele é (ii) desigual, seja em premissas, interesses, e, mesmo, em qualidade.

Não é de se espantar. A academia jurídica brasileira é uma enormidade. Em meados de 2014, havia 1284 cursos de Direito no Brasil. Para uma população de cerca de 200 milhões de pessoas, o Brasil é o país com o maior número de cursos de Direito per capita do planeta. ${ }^{15}$ Apenas para se ter noção comparativa, Portugal, conta com onze cursos de Direito. ${ }^{16}$

Tal gigantismo reflete-se nos programas de pós-graduação em Direito em sentido estrito, em cuja órbita se dá boa parte do debate sobre os aspectos jurídicos da regulação da economia. Em 2013, havia oitenta e um cursos de mestrado; trinta e um doutorados acadêmicos, e um doutorado profissional. ${ }^{17}$ Daí que a produção bibliográfica destas centenas de discentes e docentes, que eventualmente se soma à de milhares de advogados ligados à área, é inabarcável.

Há polos de influência - algumas universidades associadas aos centros econômicos e políticos do Rio de Janeiro, São Paulo, Minas Gerais, Brasília, e alguns programas de pós-graduação no Sul -, mas o debate, feito atualmente por muitos, incorpora muitas vozes. Não é incomum que, ao se mudar de estado, mudem radicalmente as referências bibliográficas, os métodos, os interesses. Afora poucos autores, tidos por clássicos, e que há alguns anos passaram a cuidar de aspectos jurídicos da regulação - por todos, cite-se Celso Antônio Bandeira de Mello ${ }^{18}$ - , o debate jurídico sobre regulação econômica, no Brasil, é mais local do que nacional.

Existem aspectos naturais e positivos disso. $\mathrm{O}$ autor amazonense que estuda a regulação ambiental dos rios da região incorpora inegável saber local, para falarmos com Gertz. Mas a diversidade radical pode esconder, também, ausência de diálogo, redundância de pesquisas, insubmissão à crítica, empoderamento de elites cognitivas paroquiais. A tarefa, aqui, talvez seja a de preservar a pluralidade, mas reduzindo o desnivelamento qualitativo (mais sobre isso no item 6 , abaixo).

Nosso debate sobre o Direito Regulatório é, ainda, caracteristicamente (iii) voltado ao Estado. ${ }^{19}$ Decerto que há algo de necessário nisso: regulação da economia é, em sua grande parte, regulação pública da economia. Mas as evidências indicam algo além. Em muitos casos, mercê de o debate girar em torno ao Estado, chega-se a certa naturalização da regulação pública. Se regular é, em certo sentido, sempre regular mais - à conta da necessidade de as burocracias justificarem publicamente sua existência ${ }^{20}-$, o foco do debate jurídico acaba sendo mesmerizado a tal linha de ação. 
Assim, obras jurídicas fundacionais sobre Direito Regulatório são voltadas à figura das agências reguladoras. ${ }^{21}$ Ainda hoje são relativamente escassos os textos dedicados à autorregulação sob perspectiva jurídica. ${ }^{22}$ Mesmo iniciativas sobre como incrementar a qualidade da regulação perguntam o que as agências reguladoras e demais instâncias públicas podem ou devem fazer para tanto. Encantados ou desencantados com a regulação setorial, o ponto focal de nossas esperanças ou críticas é sempre o Estado.

Além destas três características, típicas do debate jurídico sobre regulação da economia, mas compartilhadas com o debate jurídico em geral, há uma quarta, ainda mais indistintamente compartida com a academia jurídica como um todo. ${ }^{23}$ É a cordialidade. Em razão da não-separação entre os mundos do saber e do poder, a doutrina brasileira é composta, em boa parte, por advogados (em sentido amplo: defensores, advogados públicos e privados, promotores) e juízes. Por que se arriscar a perder dinheiro ou reputação comprando brigas? Por que deixar de ser promovido ao tribunal? São diversos os custos políticos e econômicos intrínsecos a esta questão.

Não se trata necessariamente de cordialidade real, mas de posicionamento estratégico diante de um sistema de incentivos. Como não há critério claro de averiguação da qualidade no Direito - afirma-se que a pesquisa em Direito é metodológica e institucionalmente menos desenvolvida do que a das demais ciências sociais $^{24}$-, surge a narrativa das personagens. $O$ Direito feito por juristas. Desse modo, alianças interindividuais passam a ser decisivas. Existem, é claro, discordâncias dentro de cada grupo; mas são pontuais. Grandes discordâncias só são toleradas entre grupos inteiros, em relação aos quais já se franqueou a disputa. É dizer: há partidas apenas entre times. A regra é a cordialidade pública (ainda que ela possa, por vezes, dissimular a crítica privada). ${ }^{25}$

Metodológica e conceitualmente sincrético, desigual em interesses e resultados, mas quase sempre mirando no Estado, o debate brasileiro sobre regulação da economia, feito sob a pressão da cordialidade estratégica, possui cronologia própria. É o tema dos próximos itens.

\section{ANTIGAMENTE: A PRÉ-HISTÓRIA DO DIREITO REGULATÓRIO BRASILEIRO}

A pré-história do Direito Regulatório brasileiro é a fase em que a regulação da economia não se percebia existente, e o próprio Direito Regulatório não era. Era Direito Administrativo, ou Direito Público Econômico, ou só Direito Econômico. ${ }^{26} \mathrm{O}$ debate jurídico fazia-se essencialmente constitucional, afrancesado, e doutrinário em sentido "puro", isto é, voltado a argumentos tirados da interpretação de dispositivos constitucionais, textos de lei, e afirmações de autores de livros de Direito.

Não existiam agências reguladoras. Isso não quer dizer que a atividade de regulação da economia, entendida em sentido amplo - fixar normas de condutas 
de agentes econômicos e praticar atos administrativos a elas afetos (licenças, autorizações econômicas etc.) - inexistisse. Existia, mas sem levar este nome, muito menos despertar as potencialidades que hoje se lhe reconhece. ${ }^{27}$

A partir dos anos 30 do século passado, com a intervenção do Estado brasileiro na economia em função do modelo getulista de desenvolvimento, surgiram os famosos institutos - o Instituto Brasileiro do Açúcar e do Álcool (1933); o Instituto Nacional do Sal (1940); o Instituto Nacional do Pinho (1941); o Instituto Brasileiro do Café (1952) -, tidos, por Mário Masagão, como espécies de "autarquia de economia". ${ }^{28}$ Tais autarquias não possuíam dirigentes com mandato, muitas eram ligadas diretamente à Presidência (como nos casos do Instituto do Sal e do Açúcar e do Álcool), não se cogitava que tivessem poder normativo, e muito menos estavam abertas à participação social. Com alguma dose de interpretação do passado à luz do presente, pode-se, entretanto, enxergá-los como antecessores remotos das agências reguladoras.

O debate jurídico sobre regulamentos expedidos pela Administração Pública fazia-se em termos binários. "Regulamento de execução" era válido; "regulamento autônomo", não. Fonte da regulação eram as leis; admitia-se, pontualmente, autorregulação privada. Por vezes, o Executivo federal intervinha diretamente na economia, controlando preços e fixando condutas (como por meio da Superintendência Nacional do Abastecimento - a SUNAB). ${ }^{29}$

Em síntese, a pré-história da regulação da economia brasileira contou com autarquias econômicas, controle da Administração central, e intervenções pontuais e diretas do Executivo federal. Em termos de debate jurídico, o Direito Regulatório não existia - era Direito Administrativo ou Direito Econômico -; regulação era sinônimo de legislar ou de expedir regulamentos executivos; regulamentos autônomos existiam apenas para ser abjurgados; e o debate se voltava às raízes francesas do Direito Administrativo, e, operacionalmente, a argumentos tirados de textos normativos e/ou das cogitações de autores de livros e artigos de Direito.

\section{ONTEM: A ETAPA CONCEITUAL-CONSTITUCIONAL}

Com o surgimento da primeira agência reguladora federal, a Agência Nacional de Energia Elétrica, em $1996^{30}$, o Brasil ingressou num processo de agencificação $0^{31}$, ou seja, de criação de agências reguladoras, especialmente federais. ${ }^{32,33,34}$ Isso representou mudança significativa para o Direito Regulatório brasileiro. Em primeiro lugar, pode-se dizer que ele foi criado a partir daí. Até então, discutia-se, nos meios jurídicos, a regulação da economia, mas em bases difusas e/ou em sentidos diferentes do que viria a se consolidar a partir de então. Nos anos noventa, o Direito Regulatório tomou consciência de si a partir de sua cristalização institucional: a figura da agência reguladora. Eis, então, a etapa conceitual-constitucional.

A etapa é, ao mesmo tempo, conceitual e constitucional. Neste período, buscava-se entender o que poderiam ser estas novas autarquias, ditas especiais 
por suas leis de criação. Em que consistiria seu "regime jurídico especial"? Teriam elas algo a ver com as executive agencies americanas? Com as independent agencies, talvez? Com as agências europeias? Mas também se procurava identificar seu encaixe constitucional. A Constituição da República de 1988, com vasta gama de poderes enfeixadas na figura do Presidente, poderia conviver com autarquias avessas a que este exercesse, com o auxílio de seus ministros, a direção superior da Administração Pública (art. 84, II, da CRFB-88)?

O debate jurídico do período foi intenso. Esta é, por assim dizer, a fase heróica do Direito Regulatório brasileiro: mal nascia e já chegava ao apogeu (em especial, como se descobriria depois, quanto à importância atribuída às agências reguladoras pela orientação política do poder central). Muitas das principais obras sobre o tema, - até hoje relevantes -, foram lançadas na época. ${ }^{35}$ Dentre diversas perguntas lançadas na fase, pode-se destacar, por sua recorrência e importância, as seguintes:

(i) Qual a legitimidade democrática que perpassa a atuação das agências reguladoras? Há algum déficit democrático em sua atuação? Como elas se posicionam dentro da tripartição das funções estatais?

(ii) Qual o papel das audiências e consultas públicas no incremento da adesão dos administrados às condutas propostas pela Administração Pública? Tais instrumentos desempenham algum papel em relação à representatividade das agências reguladoras?

(iii) Agências reguladoras possuem poder normativo? Caso possuam, qual o mínimo de densidade legislativa que as leis devem possuir para operar essa delegação legislativa imprópria? As leis podem se deslegificar, isto é, dispor que, para certos assuntos, dali para frente, agências reguladoras (e/ ou outras entidades ou órgãos administrativos) poderão sobre eles tratar por meio de regulamentos?

(iv) As leis de criação de agências reguladoras podem limitar o presidente da República quanto à indicação e à exoneração de diretores? Se os mandatos de tais dirigentes não coincidem com o do presidente da República, há violação à soberania popular?

(v) Existe uma discricionariedade administrativa técnica e um mérito técnico, - em paralelo à discricionariedade administrativa "pura" e ao mérito administrativo -, a legitimar a atuação das agências?

(vi) Como se deve operar a revisão judicial das escolhas regulatórias? Tribunais de contas podem rever o mérito de decisões de agências? É compatível com um regime de autonomia reforçada a admissão de recursos hierárquicos impróprios tirados de decisões destas autarquias? Elas devem possuir corpo jurídico próprio?

(vii) Como se dá o regime da responsabilidade civil das agências reguladoras? No que consiste a omissão regulatória?

Outras perguntas poderiam ser indicadas. Seja como for, o que importa ressaltar é o dinamismo da época: dúvidas eram lançadas; respostas, cogitadas; entre os que saudavam as agências como "instrumentos do fortalecimento do 
Estado" ${ }^{36}$, e os que as enxergavam como "repartições burocráticas" ${ }^{37}$, restou a importância de um período fundacional.

Eram as dores do parto. O Direito Regulatório brasileiro nascera, e sofria seu batismo de fogo sob uma chuva de dúvidas.

\section{HOJE: A ETAPA EFICACIAL}

Nem todas as perguntas da etapa conceitual-constitucional foram respondidas. Algumas, sim. Outras, ainda não. Outras, dificilmente o serão.

Das respostas a que (tentativamente) se chegou, pode-se compendiar as seguintes. Há legitimidade na atuação das agências, mas que se expressa de modo diferente da legitimidade das urnas. Audiências e consultas são importantes para reduzir a assimetria de informações entre reguladores e regulados, mesmo que estejam longe de representar alguma panaceia aos problemas regulatórios - aliás, elas trazem outros tantos. Na prática, agências possuem poder normativo, embora talvez não para assuntos muito importantes. Limites à nomeação e exoneração de dirigentes são constitucionais. Discricionariedade técnica talvez exista, mas isso não é blindagem para a revisão judicial sobre escolhas regulatórias. A recomendação é que o Judiciário se autocontenha ao efetuar tais revisões; recomendação, na prática, não inteiramente aceita. Tribunais de contas podem controlar a atividade-fim de agências. Em casos excepcionais, recursos hierárquicos impróprios são aceitos.

Com a sedimentação de certa cultura da regulação em nosso país, e a pacificação, esquecimento ou resignação quanto a algumas polêmicas, passou-se à etapa eficacial, a fase que se vive agora, em que a pergunta não é mais "quem somos”, mas a dúvida sequencial - "para onde (e como) vamos”. É bom lembrar que, em termos institucionais, as agências reguladoras federais não vivem seu melhor momento. Muitas deliberam sem que a totalidade de seus dirigentes, ou ao menos parte razoável deles, hajam sido nomeados. Nota-se certo represamento de recursos orçamentários. E os mundos da técnica e da política, para o bem e para o mal, não parecem ser tão distantes como pressupunha a narrativa que lhes justificou o ingresso no ordenamento brasileiro. Não temos as agências reguladoras de nossos sonhos; temos as de nossas possibilidades.

Antes de tudo, na fase eficacial, chegou-se à conclusão de que toda regulação é, sempre, regulação setorial. As grandes narrativas, também aqui, acabaram. O debate jurídico sobre a regulação econômica tem que ser debate sobre a regulação do setor elétrico; sobre a regulação do tabaco; sobre a regulação do gás natural. Et coetera.

Fixada esta premissa, novos objetos de estudo passaram a interessar aos estudiosos. Discussões sobre a qualidade da regulação. Propostas de fixação de índices de qualidade regulatória. Reflexões sobre boas práticas regulatórias. ${ }^{38}$ Debates sobre a governança regulatória, muitos deles centrados na figura nascente da análise de impacto regulatório. ${ }^{39} \mathrm{E}$, como cogita-se que Brasil possua um Poder 
Judiciário bastante ativista, surgem propostas de metrificação da interação entre agências, Judiciário e Legislativo. ${ }^{40}$

Aliás, assiste-se à ascensão, também no Direito Regulatório, de perspectivas empíricas do estudo do Direito. Audiências públicas passam a ser objeto de verificação pessoal por observadores-participantes. ${ }^{41} \mathrm{Com}$ a ascensão da comunicação em tempo real e a internacionalização da academia brasileira, perdem valor as abordagens de pura e simples apresentação/importação de conteúdos estrangeiros. Isso não quer dizer que o Direito estrangeiro perdeu sua influência. Ao contrário: ele é mais influente do que nunca, em especial o que vem dos Estados Unidos - em conteúdo e em método. O Direito Regulatório brasileiro de 2015 parece ser menos o direito conceitual do Conselho de Estado francês, e mais o direito das policies, da interdisciplinaridade como técnica (o fato de ser o direito das agências reguladoras já diz muito.) Vive-se momento em que o lema parece ser menos abstração, e mais experiência.

Em consequência, surgem novos temas. Dentre eles, a abordagem da economia comportamental - de que muito se fala no Brasil, espelhando o debate norte-americano, ainda que pouco se pratique -, é bastante exemplificativa dos tempos de hoje. Quem diria que especialistas em Direito Regulatório e em Direito Administrativo estariam debruçando-se sobre práticas que, em muitos casos, parecem próximas ao marketing? Sem falar que um advogado, atuante junto a projetos de infraestrutura pública, é, em boa parte do tempo, menos um profissional do Direito em estilo clássico - menos um "jurista" -, e mais um microeconomista versado em leis e em comportamentos da Administração.

A etapa eficacial pressupõe um foco principal - a eficácia da regulação - , mas, dado que nosso debate sobre regulação é desigual (v. item 2, acima), ela conviverá com elementos da fase anterior. Num país continente como o Brasil, há quem esteja cogitando de métricas para índices setoriais de regulação, e há quem ainda esteja se perguntando se agências reguladoras possuem poder normativo.

Além disso, há indagações da etapa conceitual-constitucional ainda não respondidas - se é que o serão algum dia - o que justifica sua permanência. Importa observar também que, se se verifica que as agências reguladoras federais vivem má fase, a circunstância impactará nos debates sobre a qualidade da regulação, reenviando debates da fase eficacial (v.g., a qualidade da regulação) a debates da fase anterior (a autonomia das agências).

Feitas estas observações, é hora de encerrar o texto, retomando, em tom propositivo, as características do debate jurídico sobre regulação econômica.

\section{ENCERRAMENTO: DUAS PROPOSTAS PARA O NOVO VINTÊNIO DO DIREITO REGULATÓRIO BRASILEIRO}

Se é verdade que nosso debate é sincrético, desigual, e voltado ao Estado, há pontos em que ele poderia ser aperfeiçoado? Certamente. Tais características não são propriamente defeitos; há, nelas, muito que se poderia debitar na conta 
de representações tradicionais de nosso caráter como nação. Alguém poderia dizer, por exemplo, que nosso sincretismo metodológico é projeção de nosso sincretismo étnico e/ou cultural. Não se vai a tanto, mesmo porque há dúvidas sobre se tais representações são válidas para além do estereótipo. ${ }^{42}$ Mas há, sim, no debate nacional, aspectos subótimos.

De modo simétrico à apresentação das características do debate, vai-se indicar, aqui, duas linhas de ações direcionadas à redução de tais aspectos.

\section{(1) Corrigir o que há de ruim na desigualdade}

Desigualdade pode ser reflexo de saudável sincretismo. Mas pode ser desequilíbrio; fraqueza num dos polos. No Brasil, talvez se trate de um pouco das duas coisas. Aí, o que há de ruim na desigualdade pode ser neutralizado com uma ênfase na difusão de conhecimento, especialmente online; na adoção de práticas acadêmicas de alto nível (por exemplo, o reforço de congressos científicos de fato, com elaboração de papers); numa maior institucionalização da academia jurídica, com a busca pela adoção de padrões de imparcialidade (a gerar, por exemplo, revistas acadêmicas com alto índice Qualis); na criação de comunidades nacionais de debate e troca de informação. O ideal é que sejamos plurais - diversos, mas em alto nível, e não desiguais.

\section{(2) Construir uma teoria própria da regulação econômica}

Esta linha de ação tem a ver com a característica de nossa teoria ser metodologicamente sincrética. Em parte, o sincretismo decorre de fenômeno prévio: a importação descontextualizada de teorias jurídicas. Até meados dos anos 90, produto bom era o importado. De lapiseiras a roupas, havia certo fascínio pelo produto estrangeiro. Se muito desse fascínio ficou pelo caminho, em partes da teoria e da dogmática jurídica ele resiste. Importa mais saber o que Dworkin escreveu a respeito da mais recente decisão da Suprema Corte americana, e tentar, no que der, aproveitá-la no Brasil, do que ousar refletir autonomamente sobre nossos problemas.

Não precisamos viver a vida dos outros. O que não significa, é claro, que devamos rejeitar aportes estrangeiros. São úteis, e a cada dia mais adotados. O problema é a transmigração descuidada. Por exemplo: ao importar o modelo das agências reguladoras, cogitou-se que funcionariam como nos EUA. Só que, lá, elas são resposta ao controle congressual da Administração Pública. Aqui, vivemos o hiperpresidencialismo. Não é de se espantar que, entre nós, haja contingenciamento orçamentário em relação a seu orçamento; alteração de seu regime jurídico por leis de iniciativa privativa do chefe do Executivo. Supõe-se que a dominação presidencial das agências é decorrência de nosso regime jurídico-político. ${ }^{43} \mathrm{~A}$ intenção era a de que funcionassem como autoridades independentes. Na prática, há quem fale que são autarquias glorificadas. Mas é claro: se se importasse a prática jurídico-política dos EUA, elas poderiam ser independentes. Só que isso não é possível. Onde foi que erramos? 
Na importação acrítica. É mister construir teoria jurídica própria da regulação econômica. Nossos Direito, política, economia e sociedade possuem características, que, se parecidos com os deste ou daquele país, são, na essência, únicos. Urge que analisemos nossos problemas com instrumentos afinados para nós mesmos. Algumas indicações para reflexão: ${ }^{44}$

- Como se disse, as agências reguladoras são modelo que veio dos Estados Unidos. Mas, lá, não há iniciativa privativa do Executivo para projetos de lei. Não há a figura do contingenciamento de recursos orçamentários. Aliás, até mesmo alguns órgãos públicos americanos possuem autonomia que, na prática, é maior do que a de algumas de nossas agências. $\mathrm{O}$ que a dominação presidencial implica para nossa teoria regulatória?

- A regulação brasileira subsiste num ambiente de hiperjudicialização. Isso pode levar a uma teoria da regulação econômica em que Judiciário é participante ativo, ao invés de corretor (desejavelmente autocontido) de rumos? Em outras palavras, será que não seria o caso de, em vez de lamentar a invasão do mérito técnico, buscar formas de se incorporar o Judiciário ao processo normogenético, fiscalizatório e executivo das agências?

- Possuímos órgãos com enorme capital político e jurídico, como o Ministério Público e os tribunais de contas. Em que medida eles impactam a teoria da regulação? Serão eles instâncias reguladoras autônomas? Há competição pelo capital simbólico de quem está "regulando melhor"? Existe um "perfeccionismo regulatório"? Existe a produção pragmática de um "estado de omissão regulatória” de molde a justificar a intervenção dos tribunais de contas e/ou do MP?

- Temos propensão a aceitar, e mesmo a pedir, o paternalismo estatal. De resto, nossa Constituição da República legitima-o politicamente. Como isso afeta a atuação da regulação pública da economia? Nos Estados Unidos, cogita-se do paternalismo libertário como opção a intervenções restritivas. ${ }^{45}$ Será que, no Brasil, a estratégia - não obstante méritos ou deméritos - seria desnecessária?

- Vivemos numa federação em três níveis, com órgãos legislativos em todos os entes, e profusão de competências legislativas e administrativas comuns. Qual o impacto desse sistema de incentivos na efetividade da regulação pública da economia?

- Hoje, uma das mais impactantes estratégias regulatórias junto à economia brasileira é a atuação das estatais. A endorregulação tem, entre nós, curso largo. Talvez precisemos de teoria jurídica da regulação da economia que não a denuncie ou recomende, mas a entenda de fato.

A primeira agência reguladora federal brasileira surgiu há quase vinte anos. Ao olhar para nossas especificidades, é tempo de identificar as contribuições de duas décadas de literatura e de prática. Mas é tempo, sobretudo, de nos fazermos pergunta chave para o próximo vintênio: por que não uma teoria brasileira da regulação para valer? 


\section{REFERÊNCIAS}

ARAGÃO, Alexandre Santos de. Agências reguladoras e a evolução do Direito Administrativo Econômico. 3· ed. Rio de Janeiro: Forense, 2003.

ARAGÃO, Alexandre Santos de (Org.) O Poder Normativo das Agências Reguladoras. Rio de Janeiro: Forense, 2006.

BARROSO, Luís Roberto. Neoconstitucionalismo e constitucionalização do direito: o triunfo tardio do direito constitucional no Brasil. In: $\mathrm{O}$ novo direito constitucional brasileiro: contribuições para a construção teórica e prática da jurisdição constitucional no Brasil. Belo Horizonte: Fórum, 2013.

BENJAMIN, Walter. Sobre o conceito da história. In: Obras escolhidas. Magia e técnica, arte e política. Ensaios sobre literatura e história da cultura. São Paulo: Brasiliense, 1987, v. 1.

BINENBOJM, Gustavo (Coord.) Agências Reguladoras e Democracia. Rio de Janeiro: Lumen Juris, 2006.

BOQUIMPANI, Bruno. A autoregulação: delineamento de um modelo policêntrico de regulação jurídica. Dissertação apresentada à Faculdade de Direito da UERJ como requisito parcial para a obtenção do título de mestre em Direito Público. Mimeo, 2010.

CAVALCANTI, Bianor Scelza; PECIE, Alketa. Reflexões sobre a autonomia do órgão regulador: análise das agências reguladoras estaduais. In: Revista de Administração Pública. Fundação Getúlio Vargas, vol. 34(5), set./out. 2000, pp. 99-118.

CAVAlCANTI, Themístocles Brandão. Princípios gerais de Direito Público. São Paulo: Atlas, 1946.

COHEN-ELIYA, Moshe; PORAT, Iddo. 2009. The Hidden Foreign Law Debate. In: Heller: Proportionality Approach in American Constitutional Law, The. San Diego Law Review. 46:367.

CUÉLLAR, Leila. Introdução às agências reguladoras brasileiras. Belo Horizonte: Fórum, 2008.

DI PIETRO, Maria Sylvia Zanella. Direito Regulatório: temas polêmicos. Belo Horizonte: Fórum, 2003.

. Parcerias na Administração Pública: concessão, permissão, franquia, terceirização, parceria público-privada e outras formas. 6. ed. São Paulo: Atlas.

FERREIRA MOTA, Paulo Roberto. Agências reguladoras. Barueri: Manole, 2003.

FRAGAlE FILHO, Roberto; VERONESE, Alexandre. A Pesquisa em Direito: Diagnóstico e Perspectivas. In: Revista Brasileira de Pós-Graduação. Brasília: Capes, v. 2, p. 53-70, 2004. 
GRAU, Eros Roberto. As agências, essas repartições públicas. In: SALOMÃO FILHO, Calixto. (Coord.) Regulação e desenvolvimento. São Paulo: Malheiros, 2002.

GUERRA, Sérgio. Agências reguladoras: da organização administrativa piramidal à governança em rede. Belo Horizonte: Fórum, 2012.

JUSTEN FILHO, Marçal. O Direito das Agências Reguladoras Independentes. São Paulo: Dialética, 2002.

LESSA MATTOS, Paulo Todescan. O Novo Estado Regulador no Brasil: Eficiência e Legitimidade. São Paulo: Singular, 2006.

MAYERSON-SCHNEIDER, Anna. The Little Supremes. In: Observer. 14 nov. 2005. Disponível em: 〈http://observer.com/2005/11/the-little-supremes〉. Acesso em: 9 jun. 2015.

MARQUES NETO, Floriano de Azevedo. Agências reguladoras: instrumentos do fortalecimento do Estado. ABAR. Disponível em: <http://www.abar.org.br/ images/publicacoes/agencias-reguladoras.pdf $>$. Acesso em: 13 jun. 2015.

MASAGÃO, Mário. Curso de Direito Administrativo. São Paulo: Max Limonad, 1959, t. 1.

MENDONÇA, José Vicente Santos de. A verdadeira mudança de paradigmas do direito administrativo brasileiro: do estilo tradicional ao novo estilo. Revista de Direito Administrativo. Belo Horizonte, Fórum, 2014, n. 265, jan./abr. 2014.

. Direito Constitucional Econômico: a intervenção do Estado na economia à luz da razão pública e do pragmatismo. Belo Horizonte: Fórum, 2014.

MOREIRA, Egon Bockman. Passado, presente e futuro da regulação econômica no Brasil. In: Revista Brasileira de Direito Público da Economia, a. 11, n. 44. out./dez. 2013.

NOBRE, Marcos. Apontamentos sobre a pesquisa em Direito no Brasil. In: Novos Estudos CEBRAP, São Paulo, jul/2003. pp. 145-154.

NUNES, Edson. Agências Regulatórias: Gênese, Contexto, Perspectivas e Controle. Revista de Direito Público da Economia, n. 2, abr./jun. 2003, pp. 163-220.

NUSDEO, Fábio. Auto-Regulação em Direito Econômico. In: Elizabeth Accioly. (Org.). Direito no Século XXI: em homenagem ao Prof. Werter Faria. Curitiba: Juruá Editora, 2008, v. 1.

OLIVEIRA, Rafael Carvalho Rezende. "Governança e Análise de Impacto Regulatório”. Revista de Direito Público da Economia (RDPE), v. 36, 2011.

PEZ, Thomas. Le Risque dans les Contrats Administratifs. Paris: LGDJ, 2013. POGREBINSCHI, Thamy. Judicialização ou representação? Política, direito e democracia no Brasil. Rio de Janeiro: Elsevier, 2011. 
RAGAZZO, Carlos Emmanuel Joppert. Regulação Jurídica, Racionalidade Econômica e Saneamento Básico. Rio de Janeiro: Renovar, 2011.

RODRIGUES JÚNIOR, Otávio Luiz. Como se produz um jurista? O modelo português - Parte 6. Consultor Jurídico. Disponível em: <http://www.conjur. com.br/2015-mar-04/direito-comparado-produz-jurista-modelo-portugues-parte\#author>. Acesso em: 10 jun. 2015.

ROMANO, Marcos Vinícius Bacellar. Audiências públicas na ANEEL e o insulamento político institucional brasileiro. Dissertação apresentada à Universidade Federal Fluminense como requisito parcial à obtenção do título de mestre em Direito. Niterói: Universidade Federal Fluminense, 2015.

SALOMÃO FILHO, Calixto. (Coord.) Regulação e desenvolvimento. São Paulo: Malheiros, 2002.

SILVA, Fernando Quadros da. Agências reguladoras: sua independência e o princípio do estado democrático. Curitiba: Juruá, 2002.

SILVA, Suzana Tavares da. Um novo direito administrativo? Coimbra: Imprensa da Universidade de Coimbra, 2010.

SILVA, Virgílio Afonso da. Interpretação constitucional e sincretismo metodológico. In: Virgílio Afonso da Silva (Org.). Interpretação constitucional. São Paulo: Malheiros, 2005.

SUNSTEIN, Cass. Legal Reasoning and Political Conflict. Oxford: Oxford University Press, 1996.

SUNSTEIN, Cass; THALER, Richard. Libertarian Paternalism is Not an Oxymoron. In: University of Chicago Law Review 70(4): 1159-1202. 2003.

VALENTE, Patrícia Pessôa. Análise de impacto regulatório: uma ferramenta à disposição do Estado. Belo Horizonte: Fórum, 2014.

VENÂNCIO FILHO, Alberto. A intervenção do Estado no Domínio Econômico: o Direito Público Econômico no Brasil. Rio de Janeiro: Renovar, 1998 (edição fac-similar).

WEBER, Max. A “objetividade” do conhecimento nas Ciências Sociais. São Paulo: Ática, 2011.

1 Há um corte epistemológico na abordagem do texto: ele trata do debate jurídico, quer dizer, daquele que é centrado na incidência de normas jurídicas e em práticas e procedimentos tipicamente operados por advogados, juízes, promotores, e profissionais associados a estas categorias. Seja como for, é impossível, num artigo que analisa a regulação da economia, deixar de resvalar em temas econômicos. É de se ver, aliás, que, a cada dia, parece ascender, na prática e na teoria, um novo paradigma de Direito Administrativo, funcionalmente mais próximo à economia. Sobre o ponto, cf. MENDONÇA, José Vicente Santos de. A verdadeira mudança de paradigmas do direito administrativo brasileiro: do estilo tradicional ao novo estilo. Revista de Direito Administrativo. Belo Horizonte: Fórum, 2014, n. 265, jan./abr. 2014.

2 De modo proposital, o título do trabalho usa a expressão "sensibilidade jurídica". O que é isso? É difícil definir, mas relativamente fácil de compreender. Sensibilidade jurídica é a soma do que os juristas debatem, 
do que os tribunais decidem, e do que o público em geral cogita. É o espírito, o mores jurídico de uma época. Por exemplo: durante o período constituinte brasileiro, a sensibilidade jurídica era toda voltada à política constitucional.

3 O estereótipo se associa à noção de "tipo ideal" (Idealtyp). Weber explica-o da seguinte forma: "Obtém-se um tipo ideal mediante a acentuação unilateral de um ou vários pontos de vista, e mediante o encadeamento de grande quantidade de fenômenos isoladamente dados, difusos e discretos, que se podem dar em maior ou menor número ou mesmo faltar por completo, e que se ordenam segundo os pontos de vista unilateralmente acentuados, a fim de se formar um quadro homogêneo de pensamento. Torna-se impossivel encontrar empiricamente na realidade esse quadro, na sua pureza conceitual, pois se trata de uma utopia. [...] Ora, desde que cuidadosamente aplicado, esse conceito cumpre as funções específicas que dele se esperam, em benefício da investigação e da representação." WEBER, Max. A "objetividade” do conhecimento nas Ciências Sociais. São Paulo: Ática, 2011.

4 BENJAMIN, Walter. Sobre o conceito da história. In: Obras escolhidas. Magia e técnica, arte e política. Ensaios sobre literatura e história da cultura. São Paulo: Brasiliense, 1987, v. 1.

5 O termo estilo não costuma ser empregado em textos de ciências sociais aplicadas. Ele se origina, e é de uso frequente, na história da arte. Também é de uso comum na estética.

6 SILVA, Virgilio Afonso da. Interpretação constitucional e sincretismo metodológico. In: AFONSO DA SILVA, Virgílio. (Org.). Interpretação constitucional. São Paulo: Malheiros, 2005, pp.115-143.

7 "No caso brasileiro, como no de outros países de constitucionalização recente, doutrina e jurisprudência ainda se encontram em fase de elaboração e amadurecimento, fato que potencializa a importância das referências estrangeiras. Esta é uma circunstância histórica com a qual precisamos lidar, evitando dois extremos indesejáveis: a subserviência intelectual, que implica a importação acrítica de fórmulas alheias e, pior que tudo, a incapacidade de reflexão própria; e a soberba intelectual, pela qual se rejeita aquilo que não se tem. Nesse ambiente, não é possível utilizar modelos puros, concebidos alhures, e se esforçar para viver a vida dos outros. O sincretismo - desde que consciente e coerente - resulta sendo inevitável e desejável." BARROSO, Luís Roberto. Neoconstitucionalismo e constitucionalização do direito: o triunfo tardio do direito constitucional no Brasil. In: $\mathrm{O}$ novo direito constitucional brasileiro: contribuições para a construção teórica e prática da jurisdição constitucional no Brasil. Belo Horizonte: Fórum, 2013, p. 197, nota de rodapé $n .21$.

8 A rigor, no entanto, talvez isso não seja possível, ou, sequer, desejável.

9 RAGAZZO, Carlos Emmanuel Joppert. Regulação Jurídica, Racionalidade Econômica e Saneamento Básico. Rio de Janeiro: Renovar, 2011. pp. 237-270.

10 O princípio da proporcionalidade é lugar argumentativo que, em sua forma moderna, nasceu da doutrina alemã do século XIX, ao idear limites ao exercício do poder de polícia. Após a Segunda Guerra, o princípio passou a ser utilizado pelo tribunal constitucional daquele país como limite à atuação legislativa. Atualmente, o princípio é reconhecido em muitos países como parte do Direito Constitucional. Ele consta, inclusive, da Carta de Direitos Fundamentais da União Europeia (art. 52.1).

11 De modo geral, a jurisprudência norte-americana não é tão receptiva à noção de princípio da proporcionalidade quanto a europeia e a sul-americana. V. COHEN-ELIYA, Moshe; PORAT, Iddo. 2009. The Hidden Foreign Law Debate. In Heller: The Proportionality Approach in American Constitutional Law, The. San Diego Law Review. 46:367.

12 TAVARES DA SILVA, Suzana. Um Novo Direito Administrativo? Coimbra: Imprensa da Universidade de Coimbra, 2010, p. 35: "Em primeiro lugar, destacamos a influência que os sistemas administrativos anglo-saxónicos passaram a exercer sobre os sistemas administrativos continentais no contexto do Estado Garantidor ou Estado pós-Social, imprimindo um caráter funcional às normas jurídico-administrativas, as quais passaram também a ter de se "fundamentar" em critérios de eficiência."

13 Ainda que essencialmente francesa, mas com alguma influência do Direito norte-americano, veja-se, por exemplo, PEZ, Thomas. Le Risque dans les Contrats Administratifs. Paris: LGDJ, 2013.

14 Expressão cunhada por Cass Sunstein, e difundida no cenário norte-americano, acordos teóricos incompletos são espécies de deliberação em que os agentes acordam com o resultado sem, no entanto, concordar com a teoria mais geral que justifique a decisão. V. SUNSTEIN, Cass. Legal Reasoning and Political Conflict. Oxford: Oxford University Press, 1996.

15 Dados apresentados no Painel "O ensino jurídico, advocacia e sociedade", da XXII Conferência Nacional dos Advogados Brasileiros, promovida pela Ordem dos Advogados do Brasil e ocorrida no Rio de Janeiro em 2014. 
16 A informação foi obtida em: RODRIGUES JÚNIOR, Otávio Luiz. Como se produz um jurista? O modelo português - Parte 6. Consultor Jurídico. Disponível em: <http://www.conjur.com.br/2015-mar-04/direito-comparado-produz-jurista-modelo-portugues-parte\#author>. Acesso em: 10 jun. 2015.

17 A informação foi obtida no relatório que acompanha a avaliação trienal da Coordenadoria de Aperfeiçoamento do Ensino Superior - CAPES -, órgão do Ministério da Educação responsável pela regulação dos cursos de mestrado e de doutorado no Brasil. Ele pode ser acessado em: <http://capes.gov.br/images/ stories/download/avaliacaotrienal/Docs_de_area/Direito_doc_area_e_comiss\%C3\%A3o_16out.pdf>. Acesso em: 10 jun. 2015.

18 BANDEIRA DE MELLO, Celso Antônio. Curso de Direito Administrativo. 31. ed. São Paulo: Malheiros, 2014.

19 Este seria, quiçá, elemento de ligeira igualação entre perspectivas bastante desiguais.

20 Desenvolver em MENDONÇA, José Vicente Santos de. Direito Constitucional Econômico: a intervenção do Estado na economia à luz da razão pública e do pragmatismo. Belo Horizonte: Fórum, 2014, p. 432-434.

21 JUSTEN FILHO, Marçal. O Direito das Agências Reguladoras Independentes. São Paulo: Dialética, 2002. ARAGÃO, Alexandre Santos de. Agências reguladoras e a evolução do Direito Administrativo Econômico. 2. ed. Rio de Janeiro: Forense, 2003.

22 Mas veja-se BOQUIMPANI, Bruno. A autoregulação: delineamento de um modelo policêntrico de regulação jurídica. Dissertação apresentada à Faculdade de Direito da UERJ como requisito parcial para a obtenção do título de mestre em Direito Público. Mimeo, 2010. Dentre os clássicos, cf. NUSDEO, Fábio. Auto-Regulação em Direito Econômico. In: ACCIOLY, Elizabeth. (Org.). Direito no Século XXI: em homenagem ao Prof. Werter Faria. Curitiba: Juruá Editora, 2008, v. 1, p. 163-175.

23 Tão indistintamente compartilhada que se optou por não torná-la item à parte.

24 Indicando o "atraso relativo" da pesquisa em Direito em relação à área das ciências humanas, cf. NOBRE, Marcos. Apontamentos sobre a pesquisa em Direito no Brasil. In: Novos Estudos CEBRAP, São Paulo, jul. 2003, pp. 145-154. Em perspectiva diferente, v. FRAGALE FILHO, Roberto; VERONESE, Alexandre. A Pesquisa em Direito: Diagnóstico e Perspectivas. In: Revista Brasileira de Pós-Graduação, Brasília: Capes, v. 2, p. 53-70, 2004.

$25 \mathrm{Na}$ academia jurídica norte-americana, especula-se que, em relação a alguns professores especialmente prestigiosos, em relação aos quais se cogitaria possível vaga na Suprema Corte, opere-se uma espécie de abrandamento de opiniões. Por estratégia, eles não adotariam visões extremadas em relação a temas política ou moralmente carregados. No Brasil, a cordialidade tem razões distintas: é técnica integral de sobrevivência, e não estratégia de ascensão à Suprema Corte. Contudo, é de se imaginar se, diante da polêmica na nomeação de Luiz Edson Fachin ao STF, haja sido transmitida a mesma mensagem aos pleiteantes às futuras vagas do Supremo: "defendam platitudes". MAYERSON-SCHNEIDER, Anna. The Little Supremes. In: Observer. 14 nov. 2005. Disponível em: 〈http://observer.com/2005/11/the-little-supremes〉. Acesso em: 9 jun. 2015.

26 Característica da fase é a obra de VENÂNCIO FILHO, Alberto. A intervenção do Estado no Domínio Econômico: o Direito Público Econômico no Brasil, de 1968. Há edição fac-similar da obra, publicada pela Renovar em 1998. O autor chama o que viria a ser consagrar como Direito Regulatório de "Direito Regulamentar." O livro é bastante importante por seu aspecto descritivo. Outra obra que merece ser citada é a de Themístocles Brandão Cavalcanti, Princípios gerais de Direito Público, publicada originalmente pela editora Atlas (São Paulo) em 1946. O livro teve outras edições pela editora Borsoi.

27 "Por outro lado, o que vinha à lembrança quando se falava de regulação? Apenas uma modalidade de ato administrativo, destinado a reger o funcionamento da máquina estatal ao seu interior. Era o mínimo indispensável à execução de determinadas leis.” MOREIRA, Egon Bockman. Passado, presente e futuro da regulação econômica no Brasil. In: Revista Brasileira de Direito Público da Economia, a. 11, n. 44. out./dez. 2013.

28 MASAGÃO, Mário. Curso de Direito Administrativo. São Paulo: Max Limonad, 1959, t. 1, p. 93.

29 MOREIRA, Bockman. op. cit., p. 13.

30 A ANEEL foi criada pela lei federal n. 9.427, de 26 de dezembro de 1996.

31 DI PIETRO, Maria Sylvia Zanella. Parcerias na Administração Pública: concessão, permissão, franquia, terceirização, parceria público-privada e outras formas. 6. ed. São Paulo: Atlas. p. 180. 
32 No plano federal, depois da ANEEL, foi criada a ANATEL (lei n. 9.472/97), a ANP (lei n. 9.478/98), a ANVISA (lei n. 9.782/99), a ANS (lei n. 9.961/2000), a ANA (lei n. 9.984/2000), a ANTT e a ANTAQ (lei n. 10.233/2001), a ANCINE (MP n. 2.281/2001). Durante o governo Lula, foi criada a ANAC (lei n. $11.182 / 2005)$.

33 O marco para o processo de desestatização da economia brasileiro é anterior: é o Programa Nacional de Desestatização, criado pela lei federal n. 8.031/90.

34 Sobre agências reguladoras estaduais, - que não constituem o foco deste artigo -, v. CAVALCANTI, Bianor Scelza; PECIE, Alketa. Reflexões sobre a autonomia do órgão regulador: análise das agências reguladoras estaduais. In: Revista de Administração Pública. Fundação Getúlio Vargas, v. 34(5), set/out 2000, pp. 99-118. Ainda, NUNES, Edson. Agências Regulatórias: Gênese, Contexto, Perspectivas e Controle. In: Revista de Direito Público da Economia, n. 2, abr./jun. 2003. pp. 163-220.

35 Dentre o grande número de obras, cite-se, apenas dentre os livros, os seguintes: JUSTEN FILHO, Marçal. O Direito das Agências Reguladoras Independentes. São Paulo: Dialética, 2002. ARAGÃO, Alexandre Santos de. Agências reguladoras e a evolução do Direito Administrativo Econômico. 2. ed. Rio de Janeiro: Forense, 2003. ARAGÃO, Alexandre Santos de. (Org.) O Poder Normativo das Agências Reguladoras. Rio de Janeiro: Forense, 2006. (Há segunda edição, publicada em 2011.) SALOMÃO FILHO, Calixto. (Coord.) Regulação e desenvolvimento. São Paulo: Malheiros, 2002. DI PIETRO, Maria Sylvia Zanella. Direito Regulatório: temas polêmicos. Belo Horizonte: Fórum, 2003. (Há nova edição de 2009.) BINENBOJM, Gustavo (Coord.) Agências Reguladoras e Democracia. Rio de Janeiro: Lumen Juris, 2006. FERREIRA MOTA, Paulo Roberto. Agências reguladoras. Barueri: Manole, 2003. SILVA, Fernando Quadros da. Agências reguladoras: sua independência e o princípio do estado democrático. Curitiba: Juruá, 2002. LESSA MATTOS, Paulo Todescan. O Novo Estado Regulador no Brasil: Eficiência e Legitimidade. São Paulo: Singular, 2006. CUÉLLAR, Leila. Introdução às agências reguladoras brasileiras. Belo Horizonte: Fórum, 2008. GUERRA, Sérgio. Agências reguladoras: da organização administrativa piramidal à governança em rede. Belo Horizonte: Fórum, 2012.

36 MARQUES NETO, Floriano de Azevedo. Agências reguladoras: instrumentos do fortalecimento do Estado. ABAR. Disponivel em: < http://www.abar.org.br/images/publicacoes/agencias-reguladoras.pdf $>$. Acesso em: 13 jun. 2015.

37 GRAU, Eros Roberto. As agências, essas repartições públicas. In: SALOMÃO FILHO, Calixto. (Coord.) Regulação e desenvolvimento. São Paulo: Malheiros, 2002.

38 Boa parte das discussões sobre boas práticas regulatórias ocorrem no bojo de programas como o PRO-REG, Programa de Fortalecimento da Capacidade Institucional para Gestão em Regulação, vinculado à Casa Civil da Presidência da República. Algumas agências reguladoras federais - a ANVISA e a ANS, por exemplo - lançaram manuais de boas práticas. Consultar em <www.regulacao.gov.br>.

39 Sobre o ponto, v., dentre outros, VALENTE, Patrícia Pessôa. Análise de impacto regulatório: uma ferramenta à disposição do Estado. Belo Horizonte: Fórum, 2014. OLIVEIRA, Rafael Carvalho Rezende. "Governança e Análise de Impacto Regulatório". In: Revista de Direito Público da Economia (RDPE), v. 36, 2011. MENDONÇA, José Vicente Santos de. Direito Constitucional Econômico: a intervenção do Estado na economia à luz da razão pública e do pragmatismo. Belo Horizonte: Fórum, 2014. p. 426-431.

40 Para se ficar apenas sobre a discussão quantitativa do chamado "ativismo judiciário", cf. o célebre estudo de POGREBINSCHI, Thamy. Judicialização ou representação? Política, direito e democracia no Brasil. Rio de Janeiro: Elsevier, 2011.

41 Interessante experiência pode ser encontrada em ROMANO, Marcos Vinícius Bacellar. Audiências públicas na ANEEL e o insulamento político institucional brasileiro. Dissertação apresentada à Universidade Federal Fluminense como requisito parcial à obtenção do título de mestre em Direito. Niterói: Universidade Federal Fluminense, 2015. Mimeo.

42 Embora, é claro, se o estereótipo é suficientemente forte, ele próprio pode vir a ser fonte de práticas sociais. Portanto, se nossa representação estereotípica como povo "mestiço, sincrético" for muito intensa, pode ser que passemos a nos sentir desta forma, e, daí, a agir com base num padrão de expectativas tirado destas representações.

43 PRADO, Mariana Mota. Presidential Dominance from a Comparative Perspective: The Relationship between the Executive Branch and Regulatory Agencies in Brazil". In: ACKERMAN, Susan-Rose (Coord.) Comparative Administrative Law. Edward Elgar, 2010.

44 Algumas dessas indagações foram apresentadas anteriormente em prova de aula do concurso público para provimento do cargo de professor adjunto de Direito Administrativo da UERJ.

45 SUNSTEIN, Cass; THALER, Richard. Libertarian Paternalism is Not an Oxymoron. In: University of Chicago Law Review 70(4): 1159-1202. 2003. 


\title{
STAGES OF BRAZILIAN LEGAL STUDIES ABOUT ECONOMIC REGULATIONA
}

\begin{abstract}
:
At first, the paper examines three features of Brazilian legal studies about public regulation in economy: they are syncretic, uneven, and state-focused. Next, the three stages that Brazilian regulatory studies have had are presented: in the beginning, a "pre-historic" stage, when regulatory law was still not a consolidated field, and therefore broached through Constitutional and Administrative Law. Then, in the nineties, regulatory studies entered in a conceptual stage, focused on constitutional justification for normative powers of independent regulatory agencies. Nowadays, regulatory legal studies are mostly dedicated to assessing the quality of regulation. The article concludes by suggesting two lines of action to create a more original, proficuous legal debate on economic regulation.
\end{abstract}

Keywords: Administrative law. Economic Law. Regulation. Regulatory Agencies.

Submetido: 16 dez. 2015

Aprovado: 5 jan. 2016 